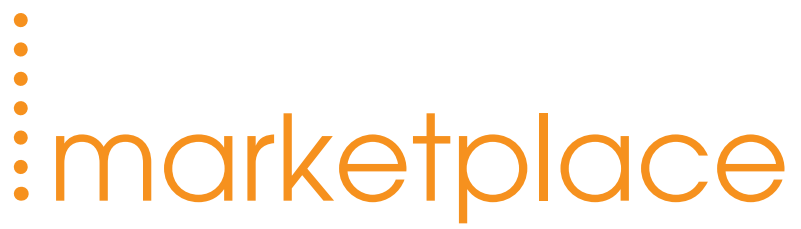

\section{Popular sample packs}

Molar's TePe sample packs have proved so popular that Molar is now making them available for surgeries to purchase.

Each pack contains eight TePe interdental brushes — one of each size from the range from the smallest (Pink $0.4 \mathrm{~mm}$ ), through to the largest (Grey $1.3 \mathrm{~mm}$ ). Each pack also comes with a travel cap. The sample pack is ideal for those patients with a number of different sized interproximal spaces who need to be able to try a selection of sizes before deciding on which they feel most comfortable with. The cost

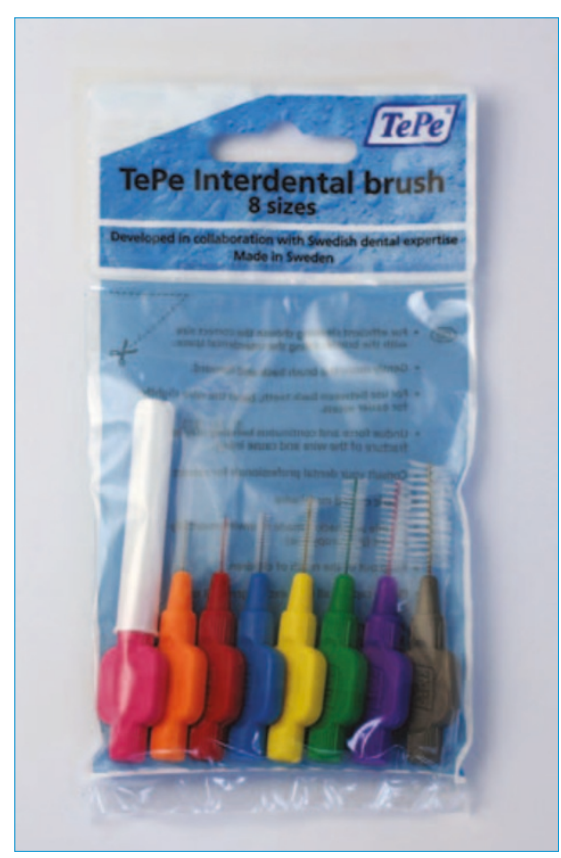
per pack is $\mathfrak{£} 1.89$ which is 24 pence per brush. However, if you prefer to size TePe brushes on patients yourselves, then the TePe surgery refill pack offers even better value, working out at just 19 pence each.

This pack contains 32 brushes including one travel cap per brush (excluding grey) and 12 patient information leaflets. Both the packs are available from most dental wholesalers. For further information visit www.molarltd.co.uk.

\section{A healthier lifesmile}

A mouth watering range of new waiting room materials have been produced to stimulate interest in Sonicare which feature the theme 'A healthier lifesmile', The campaign high-

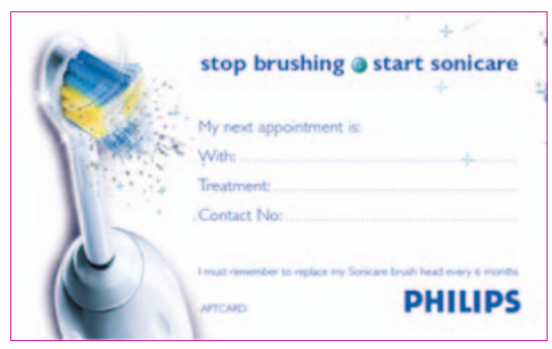

lights the importance of a healthy lifestyle - which naturally includes caring for the teeth. To complement the campaign, a £10 cash-back incentive has been initiated to stimulate interest. The materials for the dental practice include posters, A4 and A5 sized showcards, leaflets which can be posted or inserted in a leaflet dispenser, and patient appointment cards.

Also free for every practice are three easy-to-read-and-understand leaflets which have been produced to educate patients about the risks of periodontal disease and coronary heart disease, diabetes and preterm low birth weight babies. These are complemented by a general overarching leaflet about the newest Sonicare, the e9000 — which explains the benefits of the new mini brush head and two speed power handle.

\section{Educate your neighbours}

Canadian based company, Patient News Publishing, has recently launched its Patient and Neighbourhood Newsletter Programmes to the UK dental marketplace. The newsletter programmes, which follow a unique tried and tested system, have been designed to educate, inform and expand patient knowledge. It believes this provides increased levels of understanding between

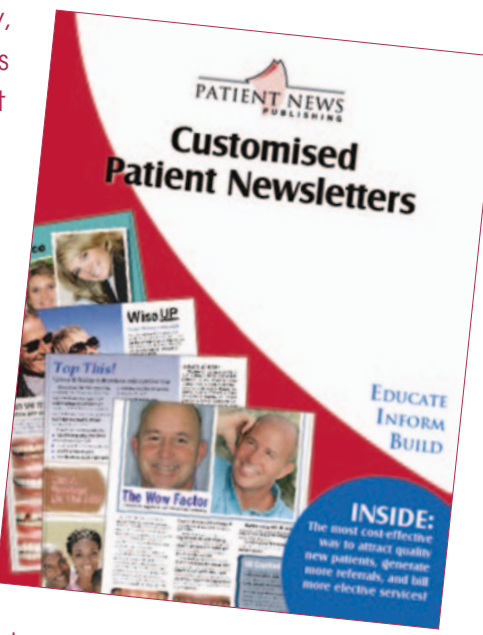
dentist and patient, which in turn prompts further questions about cosmetic and preventive dentistry services. Existing patients receive information in the comfort and security of their homes to build and strengthen patient loyalty and prospective patients who live around the practice are targeted with the neighbourhood newsletter programme.

\section{Sugarfree gum launch}

The Wrigley Company has re-launched the Orbit Complete range to the dental profession. It replaces the Orbit Professional, and white, Orbit Ice White, Orbit Spearmint and Orbit Peppermint products. All Orbit Complete products contain Xylitol, a natural sugar that inhibits the growth of oral bacteria and prevents the build up of plaque if chewed regularly as part of the oral health routine.

Spearmint, peppermint and strong mint are available in a unique envelope style format containing 14 soft tabs of gum. Fresh mint is available in the current 10 pack blister format. To find out more or to request a sample call freephone 08000564563 or email wrigleyoha@ideaslondon.com.

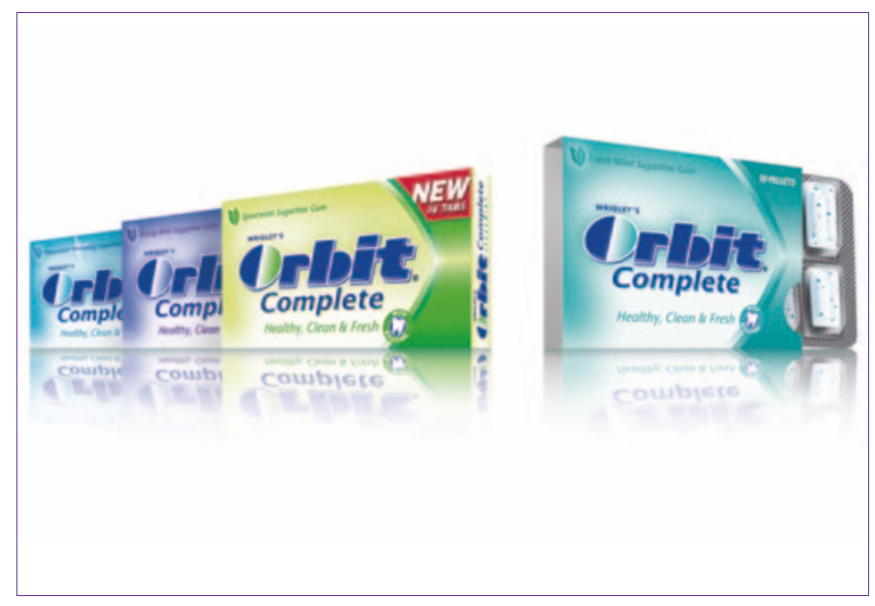

